\title{
A Case Based Methodology for Problem Solving Aiming at Knee Osteoarthritis Detection
}

\author{
Marisa Esteves ${ }^{1}$, Henrique Vicente ${ }^{2,3}$ José Machado $^{3}$, Victor Alves ${ }^{3}$, \\ and José Neves ${ }^{3(\bowtie)}$ \\ ${ }^{1}$ Departamento de Informática, Universidade do Minho, Braga, Portugal \\ marisa.araujo.esteves@gmail.com \\ 2 Departamento de Química, Escola de Ciências e Tecnologia, \\ Universidade de Évora, Évora, Portugal \\ hvicente@uevora.pt \\ ${ }^{3}$ Centro Algoritmi, Universidade do Minho, Braga, Portugal \\ \{jmac, valves, jneves\}@di.uminho.pt
}

\begin{abstract}
Knee osteoarthritis is the most common type of arthritis and a major cause of impaired mobility and disability for the ageing populations. Therefore, due to the increasing prevalence of the malady, it is expected that clinical and scientific practices had to be set in order to detect the problem in its early stages. Thus, this work will be focused on the improvement of methodologies for problem solving aiming at the development of Artificial Intelligence based decision support system to detect knee osteoarthritis. The framework is built on top of a Logic Programming approach to Knowledge Representation and Reasoning, complemented with a Case Based approach to computing that caters for the handling of incomplete, unknown, or even self-contradictory information.
\end{abstract}

Keywords: Knee osteoarthritis - Knee X-ray image feature extraction • Knowledge representation and reasoning $\cdot$ Logic programming $\cdot$ Case-based reasoning 